\title{
Severe Oxalosis Secondary to Acute Kidney Disease Contributes to Delayed Early Recovery of Renal Function
}

\section{Jing Zhou}

Kailuan General Hospital

\section{Xiaojuan Yu}

peking university first hospital

Tao Su ( $\nabla$ tao.su@bjmu.edu.cn )

Peking University First hospital https://orcid.org/0000-0002-6857-8146

\section{Suxia Wang}

Peking University First Hospital

Li Yang

Peking University First Hospital

\section{Research article}

Keywords: renal oxalosis, acute kidney disease, acute kidney injury, renal tubular injury, drug-induced

Posted Date: November 10th, 2020

DOl: https://doi.org/10.21203/rs.3.rs-103692/v1

License: (c) (i) This work is licensed under a Creative Commons Attribution 4.0 International License. Read Full License 


\section{Abstract}

Backgrounds: This study aimed to summarize and analyze the clinicopathological features of acute kidney disease patients with renal oxalosis, to improve understanding of the disease characteristics.

Methods: Data for patients with acute kidney disease (AKD) diagnosed from January 2011 to October 2018 and confirmed by renal biopsy showing oxalate crystal deposition were collected. The underlying diseases, dietary habits before disease onset, pathological characteristics of newly emerging kidney disease, renal oxalosis, and causes of AKD were analyzed. Urine volume, serum creatinine, uric acid, and electrolyte clearance were recorded. The long-term renal prognosis was observed.

Results: A total of 23 patients with AKD and renal oxalosis were included. The patients comprised 18 men $(78.3 \%)$ and 5 women $(21.7 \%)$ with a mean age of $51.6 \pm 15.9$ years. The peak serum creatinine was $669.9 \pm 299.8 \mu \mathrm{mol} / \mathrm{L}$, and $95.7 \%$ of patients had stage 3 acute kidney injury. Drug-induced AKD was the most common cause (65.2\%), followed by severe nephrotic syndrome (17.4\%). Other causes included severe glomerulonephritis, and infection. All patients had pathological changes indicating tubulointerstitial disease (TIN), and 11 patients were complicated with newly emerging glomerular disease (GD). Oxalate deposits caused by increased enterogenous oxalate absorption accounted for $26.1 \%$, and most of the causes came from new kidney diseases. Oxalate crystals were located in the renal tubule. The majority (75\%) of moderate to severe oxalate crystal deposition occurred in patients without GD. There were no significant differences in the total score for acute tubulointerstitial injury, score for tubular injury (T-IS), and score for interstitial inflammation in patients with different severities of renal oxalosis. Rate of serum creatinine decrease $(\Delta S c r \%)$ was negatively correlated with severity of oxalosis $(R=-0.542, P=0.037)$, score for acute tubular injury $(R=-0.553, P=0.033)$, and age $(R=-0.736, P=$ 0.002). $\Delta S c r \%$ at week 4 was correlated with T-IS $(R=-0.433, P=0.050)$, but was not correlated with severity of oxalosis.

Conclusions: The present findings revealed that $95.7 \%$ of AKD cases with renal oxalosis occurred in critically ill patients, secondary to kidney injury with tubular injury, and that drug-induced AKD was the most common cause. Severe oxalosis contributed to delayed early recovery of renal function.

\section{Background}

Renal oxalosis is a disease in which large numbers of oxalate crystals are deposited in the renal tubules and renal interstitium, resulting in structural and functional disorders of the kidney. It is also known as oxalate nephropathy. Oxalate is an intermediate product of energy metabolism in the liver. Classical primary hyperoxaluria is a genetic disease in which abnormal glyoxylate metabolic enzymes in the liver lead to excessive accumulation of endogenous oxalate. The clinical manifestations are chronic damage to renal function and recurrent calcium oxalate kidney stones. Oxalate is mainly excreted by glomerular free filtration in the urine and is a representative small-molecule uremic toxin. Serum oxalate levels in patients with chronic kidney disease (CKD) gradually increase with deterioration of renal function. High 
oxalate diet intake and intestinal fat malabsorption increase absorption of enterogenous oxalate, which can aggravate hyperoxaluria, leading to crystallization and inflammatory damage as adverse factors that promote CKD progression and increase the risk of cardiovascular disease [1-3].

Renal oxalosis can lead to acute kidney injury (AKI), which is frequently observed in patients after kidney transplantation and results in delayed recovery of renal allograft function. In clinical practice, oxalosis can also be found in patients with AKI without kidney transplantation, but its mechanism and participation in the process of acute injury remain unclear. However, researchers still tend to focus on case reports for this disease [4-7], which lack summaries of relevant findings. The present study aimed to summarize the clinicopathological features of 23 patients with acute kidney disease (AKD) and renal oxalosis who were diagnosed and followed up in our department, to further understand the characteristics of the disease and their effects on prognosis.

\section{Methods}

\section{Subjects}

From January 2011 to October 2018, 23 cases of AKD diagnosed according to the KDIGO criteria with renal oxalosis confirmed by kidney biopsy were collected from Peking University First Hospital. The inclusion criteria were: (1) clinical diagnosis of AKD according to the KDIGO criteria [8-9]; and (2) presence of transparent or yellowish oxalate crystals in renal tissues detected by light microscopy, with birefringence under polarized light on HE staining. The exclusion criteria were pathological diagnoses of chronic renal injury.

\section{Analysis of clinical, laboratory and imaging data}

Data on patient age, sex, underlying diseases (diabetes, hypertension, hyperuricemia, digestive system diseases, urinary system diseases, malignant tumors, other diseases), eating habits, and recent use of drugs (antibiotics, antiviral drugs, non-steroidal antipyretic analgesics) were collected. Vital signs, urine volume, medications for kidney disease during hospitalization, and renal prognosis were recorded. The evaluation criteria for renal outcomes were serum creatinine levels and percentages of serum creatinine decreases at 2 weeks to 6 months after the peak serum creatinine was observed.

Routine urine examinations, microscopic examinations of urinary sediment, and analyses of urinary protein components were performed in all patients, including urine specific gravity, $\mathrm{pH}$ value, glucose, $\mathrm{N}$ acetyl- $\beta$-D-glucosaminidase (NAG), and a1-microglobulin (a1-MG) before kidney biopsy. Data on 24-hour urinary creatinine, uric acid, and electrolytes were collected, and the solute clearance rate and excretion fraction were calculated together with the results of blood tests. All patients were examined by ultrasonography to determine whether they were complicated with kidney stones. 


\section{Evaluation of renal pathological features}

Renal biopsy specimens were examined by fluorescence, light microscopy, and electron microscopy. The pathological diagnosis and renal tubulointerstitial injury score (TiIS) were made by two experienced renal pathologists. The modified renal TilS was determined in accordance with the Banff working group classification standards [10-11], using the severities of tubular epithelial cell injury, interstitial edema, interstitial cell infiltration, tubular atrophy, and interstitial fibrosis, that they were scored 0,1,2,3,4. According to the presence or absence of tubular cell necrosis and tubulitis, they were scored 0 or 1 .The renal tubulointerstitial acute injury score (A-TilS) was defined the sum of the tubular injury score (T-IS) and interstitial acute inflammation score. The renal tubulointerstitial chronic injury score (C-TiIS) was defined as the sum of the renal tubular atrophy score, renal interstitial fibrosis score, and chronic inflammation score, which followed the same scoring rules as A-TilS.

Oxalate crystal deposition was defined as transparent or light yellow clusters or radial crystals observed by optical microscopy that exhibited birefringence under HE staining with polarized light. Based on the total numbers of oxalate crystals deposited in 10 visual fields at $200 \times$ magnification, oxalosis was divided into three types: mild, 0-5; medium, 5-10; severe, > 10 .

\section{Statistical analysis}

SPSS software version 20.0 (IBM Corp., Armonk, NY) was used for all statistical analyses to determine the severity of renal oxalosis and to compare and analyze the related influencing factors. Continuous variables with a normal distribution were expressed as mean \pm standard deviation and compared between groups by a $t$-test, while continuous variables with a non-normal distribution were expressed as quartiles and compared between groups by a nonparametric test. Classified variables were expressed by number of cases (percentage), with unordered variables compared by the chi-square test and ordered variables compared by the Wilcoxon rank-sum test. Values of $\mathrm{P}<0.05$ were considered to indicate statistical significance (bilateral test).

\section{Results}

\section{General conditions and clinicopathological features of AKD patients with renal oxalosis}

A total of 23 patients with AKD and renal oxalosis were included in the study. The patients comprised 18 men $(78.3 \%)$ and 5 women (21.7\%) with a mean age of $51.57 \pm 15.89$ years. Among them, 22 patients (95.7\%) met the criteria for AKI, 5 patients had nephrotic syndrome, and 6 patients had nephritis syndrome.

The renal biopsy examinations showed that 11 patients had glomerular disease (GD) and acute tubulointerstitial disease (tubulointerstitial nephritis [TIN]), including minimal change nephropathy, membranous nephropathy, lupus nephritis, IgA nephropathy, malignant hypertensive thrombotic microangiopathy, anti-glomerular basement membrane disease, post-infection glomerulonephritis, and 
diabetic nephropathy. The other 12 patients were diagnosed as acute tubulointerstitial disease without GD. As shown in Table 1, combination with further etiological analyses by pathology revealed that the pathogenic factors leading to AKD were drugs (15 cases, 65.2\%), severe nephrotic syndrome (4 cases, $17.4 \%$ ), severe glomerulonephritis (3 cases, $13.0 \%$ ), infection (2 cases, $8.7 \%$ ), and increased absorption of enterogenous oxalate from diarrhea or increased dietary oxalate intake through excessive consumption ( 2 cases, $26.1 \%$ ). The types of pathogenic drugs involved included non-steroidal antipyretic analgesics (NSAIDs, 53.3\%), antibiotics (5 cases, 33.3\%), antiviral drugs, platinum chemotherapeutic drugs, and traditional Chinese herbs. No cases with kidney transplantation or primary hyperoxaluria were included. The prominent risk factors contributing to renal oxalosis as listed in Table 2 were sudden emergence of new kidney diseases, while increased enterogenous oxalate absorption occurred in only 6 cases $(26.1 \%)$.

Table 1

Risk factors contributing to renal oxalosis

\begin{tabular}{|ll|}
\hline Risk factors & cases \\
\hline One identified risk factor & 17 \\
\hline New AKD & 1 \\
\hline Increased enterogenousoxalate absorption due to fat malabsorption by diarrhea & 1 \\
\hline Increased dietary intake through excessive consumption & \\
\hline More than two identified risk factors & 2 \\
\hline New AKD + Increased enterogenousoxalate absorption & 2 \\
\hline New AKD + Increased dietary intake & \\
\hline
\end{tabular}

Note: AKD, Acute kidney disease. 
Table 2

Physical and laboratory findings

\begin{tabular}{|c|c|c|c|c|c|}
\hline & $\begin{array}{l}\text { Total AKD, } \\
\text { oxalosis }(n=23)\end{array}$ & $\begin{array}{l}\text { AKD, oxalosis, with } \\
\text { GD }(n=11)\end{array}$ & $\begin{array}{l}\text { AKD, oxalosis, w/o } \\
\text { GD }(n=12)\end{array}$ & $\begin{array}{l}\mathrm{t} / \mathrm{Z} \\
\text { value }\end{array}$ & $\begin{array}{l}P \\
\text { value }\end{array}$ \\
\hline $\begin{array}{l}\mathrm{BMI} \\
\left(\mathrm{kg} / \mathrm{m}^{2}\right)\end{array}$ & $24.94 \pm 4.42$ & $24.79 \pm 5.19$ & $25.07 \pm 3.85$ & 0.14 & 0.89 \\
\hline $\begin{array}{l}\mathrm{SBP}, \\
\mathrm{mmHg}\end{array}$ & $138.9 \pm 14.3$ & $135.18 \pm 13.0$ & $142.25 \pm 15.2$ & 1.196 & 0.245 \\
\hline $\begin{array}{l}\text { DBP, } \\
\mathrm{mmHg}\end{array}$ & $82.5 \pm 9.3$ & $82.5 \pm 11.2$ & $82.5 \pm 7.7$ & 0.011 & 0.991 \\
\hline $\mathrm{BNP}, \mathrm{pg} / \mathrm{nl}$ & $\begin{array}{l}250.0 \\
(24.0,869.0) \\
(n=17)\end{array}$ & $\begin{array}{l}451.0 * \\
(179.0,2133.5) \\
(n=9)\end{array}$ & $\begin{array}{l}53.5^{\star} \\
(11.5,338.5) \\
(n=8)\end{array}$ & -2.117 & 0.034 \\
\hline $\mathrm{UV}(\mathrm{ml} / \mathrm{d})$ & $1503.6 \pm 605.8$ & $882.7 \pm 664.0$ & $1572.7 \pm 925.0$ & 2.01 & 0.058 \\
\hline UP g/24 h & $\begin{array}{l}0.21 \\
(0.06,1.85) \\
(n=22)\end{array}$ & $\begin{array}{l}2.49 * \\
(0.34,19.81) \\
(n=10)\end{array}$ & $\begin{array}{l}0.07 * \\
(0.02,0.16)\end{array}$ & -3.236 & 0.001 \\
\hline U-PH & $6.07 \pm 1.07$ & $6.55 \pm 1.15^{\star}$ & $5.63 \pm 0.80 *$ & -2.243 & 0.036 \\
\hline $\begin{array}{l}\text { U-NAG } \\
(\mathrm{U} / \mathrm{L})\end{array}$ & $\begin{array}{l}26.00 \\
(10.50,78.50) \\
(n=21)\end{array}$ & $\begin{array}{l}78.50 * \\
(32.75,181.00) \\
(n=10)\end{array}$ & $\begin{array}{l}13.00 * \\
(8.00,26.00) \\
(n=11)\end{array}$ & -2.996 & 0.003 \\
\hline $\begin{array}{l}\text { a1-MG } \\
(\mathrm{mg} / \mathrm{L})\end{array}$ & $\begin{array}{l}71.80 \\
(20.10,171.00)\end{array}$ & $\begin{array}{l}137.50 * \\
(83.30,195.75)\end{array}$ & $\begin{array}{l}27.40 * \\
(14.71,57.40)\end{array}$ & -2.613 & 0.009 \\
\hline U-Glu (\%) & $5 / 23(21.7 \%)$ & $3 / 11(27.3 \%)$ & $2 / 12^{\star}(16.7 \%)$ & 0.379 & 0.64 \\
\hline $\begin{array}{l}\text { GHbA1c } \\
(\%)\end{array}$ & $\begin{array}{l}7.05 \pm 1.22 \\
(n=12)\end{array}$ & $\begin{array}{l}6.00 \pm 0.26 \\
(n=3)\end{array}$ & $\begin{array}{l}7.40 \pm 1.21 \\
(n=9)\end{array}$ & 1.927 & 0.083 \\
\hline $\begin{array}{l}\text { SCr peak } \\
(\mu \mathrm{mol} / \mathrm{L})\end{array}$ & $\begin{array}{l}669.86 \\
\pm 299.82\end{array}$ & $\begin{array}{l}749.22 \\
\pm 289.22\end{array}$ & $\begin{array}{l}597.12 \\
\pm 302.76\end{array}$ & -1.229 & 0.233 \\
\hline $\begin{array}{l}\text { SCr } \\
\text { when } \\
\text { biopsy } \\
(\mu \mathrm{mol} / \mathrm{L})\end{array}$ & $\begin{array}{l}407.89 \\
\pm 257.14\end{array}$ & $\begin{array}{l}423.49 \\
\pm 271.52\end{array}$ & $\begin{array}{l}393.60 \\
\pm 254.48\end{array}$ & -0.273 & 0.788 \\
\hline
\end{tabular}




\begin{tabular}{|c|c|c|c|c|c|}
\hline & $\begin{array}{l}\text { Total AKD, } \\
\text { oxalosis }(n=23)\end{array}$ & $\begin{array}{l}\text { AKD, oxalosis, with } \\
\text { GD }(n=11)\end{array}$ & $\begin{array}{l}\text { AKD, oxalosis, w/o } \\
\text { GD }(n=12)\end{array}$ & $\begin{array}{l}\mathrm{t} / \mathrm{Z} \\
\text { value }\end{array}$ & $\begin{array}{l}P \\
\text { value }\end{array}$ \\
\hline $\begin{array}{l}\text { SUa } \\
(\mu \mathrm{mol} / \mathrm{L})\end{array}$ & $401.0 \pm 121.3$ & $337.6 \pm 117.9 *$ & $464.4 \pm 90.4^{\star}$ & 2.831 & 0.01 \\
\hline FeUa & $\begin{array}{l}0.21 \pm 0.14 \\
(n=10)\end{array}$ & $\begin{array}{l}0.21 \pm 0.18 \\
(n=4)\end{array}$ & $\begin{array}{l}0.22 \pm 0.13 \\
(n=6)\end{array}$ & 0.123 & 0.905 \\
\hline $\begin{array}{l}\mathrm{CCa} \\
(\mathrm{ml} / \mathrm{min})\end{array}$ & $\begin{array}{l}0.42 \pm 0.19 \\
(n=9)\end{array}$ & $\begin{array}{l}0.38 \pm 0.27 \\
(n=3)\end{array}$ & $\begin{array}{l}0.44 \pm 0.15 \\
(n=6)\end{array}$ & 0.422 & 0.686 \\
\hline $\begin{array}{l}\text { S-Pi } \\
(\mathrm{mmol} / \mathrm{L})\end{array}$ & $1.47 \pm 0.44$ & $1.46 \pm 0.55$ & $1.47 \pm 0.33$ & 0.071 & 0.944 \\
\hline $\mathrm{FePi}$ & $\begin{array}{l}0.33 \pm 0.14 \\
(n=9)\end{array}$ & $\begin{array}{l}0.27 \pm 0.22 \\
(n=3)\end{array}$ & $\begin{array}{l}0.35 \pm 0.11 \\
(n=6)\end{array}$ & 0.75 & 0.478 \\
\hline $\begin{array}{l}\mathrm{Na} \\
(\mathrm{mmol} / \mathrm{L})\end{array}$ & $138.31 \pm 3.14$ & $137.73 \pm 3.62$ & $138.85 \pm 2.67$ & 0.849 & 0.405 \\
\hline $\begin{array}{l}\text { UNa } \\
(\mathrm{mmol} / \mathrm{L})\end{array}$ & $\begin{array}{l}61.07 \pm 22.94 \\
(n=9)\end{array}$ & $\begin{array}{l}72.67 \pm 22.84 \\
(n=6)\end{array}$ & $\begin{array}{l}52.38 \pm 20.09 \\
(n=8)\end{array}$ & -1.766 & 0.103 \\
\hline $\mathrm{FeNa}$ & $\begin{array}{l}0.04 \pm 0.04 \\
(n=11)\end{array}$ & $\begin{array}{l}0.06 \pm 0.06 \\
(n=4)\end{array}$ & $\begin{array}{l}0.03 \pm 0.03 \\
(n=7)\end{array}$ & -0.841 & 0.422 \\
\hline $\begin{array}{l}\text { SK } \\
(\mathrm{mmol} / \mathrm{L})\end{array}$ & $4.14 \pm 0.77$ & $3.94 \pm 0.64$ & $4.31 \pm 0.87$ & 1.149 & 0.263 \\
\hline $\begin{array}{l}\text { UK } \\
(\mathrm{mmol} / \mathrm{L})\end{array}$ & $\begin{array}{l}19.57 \pm 9.00 \\
(n=14)\end{array}$ & $\begin{array}{l}25.67 \pm 9.67 \\
(n=6)\end{array}$ & $\begin{array}{l}15.00 \pm 5.29 \\
(n=8)\end{array}$ & -2.657 & 0.021 \\
\hline $\begin{array}{l}\text { UK } \\
(\mathrm{mmol} / \mathrm{d})\end{array}$ & $\begin{array}{l}37.34 \pm 16.45 \\
(n=14)\end{array}$ & $\begin{array}{l}44.77 \pm 19.17 \\
(n=6)\end{array}$ & $\begin{array}{l}31.76 \pm 12.53 \\
(n=8)\end{array}$ & -1.539 & 0.15 \\
\hline UK/UCREA & $\begin{array}{l}4.17 \pm 2.36 \\
(n=12)\end{array}$ & $\begin{array}{l}5.33 \pm 3.01 \\
(n=5)\end{array}$ & $\begin{array}{l}3.33 \pm 1.48 \\
(n=7)\end{array}$ & 5.010 & 0.049 \\
\hline
\end{tabular}

Note: BMI, body mass index; SBP, systolic blood pressure; DBP, diastolic blood pressure; BNP, atrial natriuretic peptide; UV, urine output volume; UP, urinary proteinuria; U-PH, urine $\mathrm{PH}$; U-NAG, urinary NAG enzyme; a1-MG, a1-microglobulin; $\mathrm{SCr}$, serum creatinine; $\mathrm{CCa}$, clearance of calcium; UK/UCREA, urinary potassium creatinine ratio. 
Underlying diseases included one case with a history of kidney stones and 2 cases (8.7\%) diagnosed with kidney stones by ultrasonography after hospital admission. One case (4.3\%) underwent total gastrectomy for gastric cancer, but without chronic diarrhea. There were 11 patients with diabetes $(47.8 \%)$ and 17 patients with hypertension (73.9\%). The mean body mass index (BMI) was $24.94 \pm 4.42 \mathrm{~kg} / \mathrm{m}^{2}$.

\section{Laboratory parameters characteristics of AKD patients with renal oxalosis}

The mean peak serum creatinine level in the patients was $669.9 \pm 299.8 \mu \mathrm{mol} / \mathrm{L}$. Twenty-two patients met the criteria for $\mathrm{AKI}$ and reached stage 3 , with 10 patients (45.5\%) receiving hemodialysis at the time of disease onset. Urine volume was significantly decreased in patients with GD, with a mean urine output of $882.7 \mathrm{~mL}$, and $63.6 \%$ showing $<1000 \mathrm{~mL}$ on the second day of admission. Patients without GD, had both higher serum $(464.4 \pm 90.4 \mu \mathrm{mol} / \mathrm{L}$ vs. $337.6 \pm 117.9 \mu \mathrm{mol} / \mathrm{L})$ and urinary $(2793.3 \pm 878.0 \mathrm{mmol}$ vs. $1791.50 \pm 1141.8 \mathrm{mmol}$ ) uric acid concentrations, but the calculated uric acid excretion fraction was similar to that in patients with GD ( $21 \%$ vs. $22 \%)$. The change in blood electrolytes was slight, and there were no significant differences in serum phosphorus $(1.47 \pm 0.44 \mathrm{mmol} / \mathrm{L})$, corrected serum calcium $(2.38 \pm 0.14 \mathrm{mmol} / \mathrm{L})$, sodium $(138.31 \pm 3.14 \mathrm{mmol} / \mathrm{L})$, chlorine $(105.02 \pm 4.86 \mathrm{mmol} / \mathrm{L})$, and potassium $(4.14 \pm 0.77 \mathrm{mmol} / \mathrm{L})$ among AKD patients with oxalosis.

Urinalysis showed that the patients had varying degrees of proteinuria, with $43.5 \%$ exhibiting microscopic hematuria. Patients with GD had more urinary protein at 0.34-19.81 g/day (median: $2.49 \mathrm{~g} /$ day), significantly higher urinary NAG enzyme, urinary a1-MG levels (median: $78.5 \mathrm{U} / \mathrm{L}$ and $137.5 \mathrm{mg} / \mathrm{L}$, respectively), and urinary microalbumin $(\mathrm{mA}) / \mathrm{a} 1-\mathrm{MG}$ ratio of 20.7 (range: 1.78-43.41) than patients without GD. In contrast, patients without GD rarely had proteinuria (range: $0.02-0.16 \mathrm{~g} /$ day; median: $0.07 \mathrm{~g} /$ day), had slightly increased urinary NAG and a1-MG levels compared with the reference values (13 $\mathrm{U} / \mathrm{mg} / \mathrm{L}$ and $27.4 \mathrm{~g} /$ day, respectively), and had a lower $\mathrm{mA} / \mathrm{a} 1-\mathrm{MG}$ ratio of $0.58 \mathrm{~g} /$ day (range: $0.35-$ $1.2 \mathrm{~g} /$ day) when compared with GD patients. The incidence of renal glycosuria was only $21.7 \%$, and oxalate crystals were observed in the urine before the kidney biopsy in only 2 patients (8.7\%).

\section{Pathological features of AKD patients with renal oxalosis}

In addition to the phenomenon of renal oxalosis, all 23 patients had the basic pathological features of acute tubulointerstitial nephritis. According to the pathological scoring criteria used in this study, the scores for tubulointerstitial injury (Table 3) showed that regardless of the presence or absence of GD, tubulointerstitial injury was most prominent and interstitial lesions were mild. Pathologically, oxalate crystals showed mild to severe diffuse distribution in the renal tubule lumen (Fig. 1) with surrounding secondary inflammatory reactions. The degree of oxalate crystal deposition was more diffuse in patients without GD, accounting for $50 \%, 8.3 \%$, and $41.7 \%$ from mild to severe, while $75 \%$ were mild and only $8.3 \%$ were severe among patients with GD. Correlation analyses showed that degree of oxalate crystal deposition was not correlated with urine volume, serum creatinine level, total proteinuria, a1-MG level, renal glycosuria, or uric acid excretion rate, and was also not correlated with pathological scores for renal tubular injury. 
Table 3

Pathological scores

\begin{tabular}{|lll|}
\hline & AKD, oxalosis, w/o GD & AKD, oxalosis, with GD \\
\hline A-TilS & $5.0 \pm 4.2$ & $5.3 \pm 3.4$ \\
\hline T-IS & $3.5 \pm 2.7$ & $4.2 \pm 2.0$ \\
H-IS & $1.5 \pm 2.4$ & $1.1 \pm 2.1$ \\
\hline C-TilS & $2.0 \pm 1.8$ & $1.9 \pm 3.4$ \\
\hline T-IS & $0.67 \pm 0.79$ & $0.64 \pm 1.21$ \\
\hline HIS & $1.33 \pm 1.16$ & $1.27 \pm 2.20$ \\
\hline
\end{tabular}

Note: AKD, acute kidney injury; GD, glomerulonephritis; A-TilS, acute tubulointerstitial injury score; T-IS, tubular injury score; I-IS, interstitial injury score; C-TiIS, chronic tubulointerstitial injury score

\section{Prognosis of AKD patients with oxalosis}

Among the AKD patients with oxalosis in this study, 7 patients received prednisone combined with immunosuppressants for new GD, and 3 patients were administered $0.5 \mathrm{mg} / \mathrm{kg}$ initial dose of prednisone for tubulointerstitial disease. During follow-up until 6 months after diagnosis, 4 patients with severe glomerulopathy never recovered their renal function and maintained a state of dialysis, while the other 19 patients recovered. When compared with the peak serum creatinine, $\Delta \mathrm{Scr}$ decreased by $50.2 \%$ at 2 weeks, $58.5 \%$ at 4 weeks, $62.5 \%$ at 8 weeks, and $67.9 \%$ at 24 weeks. Renal function in one patient with severe oxalosis caused by stubborn diarrhea showed partial remission once under supportive treatment, but deteriorated again only 4 weeks later and ended at maintenance hemodialysis after 6 months. Statistical analyses showed that decrease rate of serum creatinine after the peak $(\Delta \mathrm{Scr} \%)$ was negatively correlated with severity of oxalosis $(R=-0.542)$, T-IS $(R=-0.553)$, and age $(R=-0.736)$. Decrease in Scr at 4 weeks was correlated with T-IS $(R=-0.433)$, but had no correlation with degree of oxalosis. It was observed that occurrence of severe oxalosis contributed to delayed early recovery of renal function.

\section{Discussion}

Some drug food ingredients and metabolites in the human body can be deposited as crystals in the kidney, resulting in renal tubule obstruction and interstitial inflammation that affect renal function, with oxalate crystal deposition being the most common [12-13]. The majority of oxalate in the blood is an endogenous product formed by glyoxylate metabolism in the liver. Oxalate precursors like vitamin $\mathrm{C}$ can also be converted into oxalate through liver metabolism. The proportion of enterogenous oxalate directly derived from oxalic acid-containing food absorbed through the gastrointestinal mucosa accounts for only $10-15 \%$. Small molecules of oxalate can be removed by glomerular free filtration, and excretion via the SLC26A transporter family on renal proximal tubular epithelial cells and intestinal mucosal epithelial cells is the active pathway for oxalate clearance from the body. In disease states such as kidney failure, 
diabetes, and obesity, when oxalate cannot be fully excreted from the body through the urine and intestines, the concentration of oxalate in the blood will further increase, leading to hyperoxaluria [14]. As early as 1973, William R. Salyer and colleagues observed that oxalate crystals were frequently present in autopsy patients with acute or chronic renal injury [15]. Among maintenance dialysis patients with endstage kidney disease, the phenomenon of oxalate crystal deposition in the kidney and heart is a very serious complication, and affected $100 \%$ and $60 \%$ of peritoneal dialysis patients, respectively. At the same time, $56 \%$ of patients with acute renal failure ( $90 \%$ with acute tubular necrosis) had renal oxalosis and $8 \%$ had myocardial oxalate crystal deposition. In many subsequent studies, serum oxalate levels were directly measured. It was found that the serum oxalate level (median: $35 \mu \mathrm{mol} / \mathrm{L}$ ) in patients with CKD was more than 3 times higher than the normal range. With the recovery of renal graft function after kidney transplantation, the serum oxalate concentration decreased significantly, and had a negative correlation with the glomerular filtration rate (GFR). Thus, severely impaired renal function is one of the most important reasons for secondary hyperoxaluria. When the blood oxalate level exceeds $30 \mu \mathrm{mol} / \mathrm{L}$, the risk of oxalate crystal deposition in systemic tissues is significantly increased. Oxalate combines with calcium to form calcium oxalate crystals that are deposited in the renal parenchyma, phagocytosed by chemotactic macrophages, activate Nod-like receptors such as Nod-like receptor protein-3 (NLRP3), promote secretion of inflammatory mediators like interleukin (IL)-1 $\beta$ and IL-8, trigger tissue inflammation and oxidative stress responses [17], and aggravate renal function damage.

In 2013, the Mayo Clinic reported a large group of 65 patients with renal oxalosis diagnosed by renal biopsies. The results showed that primary hyperoxaluria, kidney transplantation, and enterogenous hyperoxaluria or excessive food intake of oxalate synthesis precursors were the three major diseases, while only $6.2 \%$ were attributed to decreased renal function [12]. A meta-analysis of the causes for secondary renal oxalosis performed by researchers at Tufts University School of Medicine in the United States showed that $88 \%$ were secondary to fat malabsorption and $20 \%$ arose by excessive dietary oxalate consumption. However, the 23 patients with AKD in the present study also had secondary oxalosis. The etiological composition was different from that reported by Western researchers where only $26.1 \%$ of patients had AKD with oxalosis caused by enterogenous or excessive oxalate intake, while only new AKD was the cause of oxalosis in these patients. Acute tubular injury was the most common pathological feature. The T-IS also serves as the key marker for predicting long-term prognosis. Among the causes of AKD, drug-induced kidney injury was the most common, and deserves special attention.

In this study, we noticed that severity of oxalosis was not correlated with serum creatinine level. Although oxalate crystal deposition was also observed in AKD patients with severe glomerular lesions such as crescentic glomerulonephritis, their degree of diffuse oxalate crystal deposition was significantly mild. Furthermore, severe oxalate crystal deposition mainly occurred in AKD patients with tubulointerstitial nephritis. It can be speculated that a decrease in GFR was not the only cause of oxalosis in patients with AKD, and that tubular injury itself may play an important role in promoting crystallization. Some researchers reported that ischemia-induced renal tubular epithelial cell injury accelerated the deposition of calcium oxalate crystals and aggravated the injury in an ethylene glycol-induced hyperoxaluria animal model [18]. In the present study, laboratory parameters reflecting the function of proximal tubules did not 
differ significantly among patients with different degrees of oxalate crystal deposition. The score for pathomorphological changes in tubulointerstitial damage were not correlated with severity of oxalate crystal deposition. It is known that reabsorption of glucose, small-molecule proteins, and uric acid in the urine is mainly completed in the S1 and S2 segments of the proximal renal tubule, while the transporter SLC26A6, which mediates oxalate excretion, is only expressed on the luminal surface of the S3 segment susceptible to ischemia. SLC26A6 ${ }^{-/-}$knockout mice showed a prominent increase in blood and urinary oxalate levels, supporting the notion that renal tubular damage in S3 significantly reduces active excretion of oxalate, which not only aggravates hyperoxaluria secondary to AKD, but also indicates that SLC26A6 down-regulation weakens the inhibitory effect on activity of the coupled citrate transporter NaDC-1, resulting in hypocitraturia that renders oxalate more likely to form crystals in urine [19].

In this study, $47.8 \%$ of AKD patients with renal oxalosis were complicated with diabetes. A previous study found that patients with obesity and diabetes were often complicated with hyperoxaluria [20]. Glyoxylate, the precursor of oxalate, is an intermediate product of energy metabolism produced by fatty acids in the liver, and was also identified as a metabolic marker closely related to occurrence of diabetes in recent studies. In addition, the oxalate transporter SLC26A6 was highly expressed not only on the surface of proximal renal tubular epithelial cells, but also in jejunal mucosal epithelial cells and pancreatic cells. Animal experiments revealed that SLC26A6 activity in the jejunal epithelium of diabetic rats was significantly decreased, leading to a decrease in oxalate excretion through the intestine, which may also promote the occurrence of hyperoxaluria.

According to a previous study on oxalate crystal deposition after kidney transplantation, the high level of oxalate in the blood of kidney transplantation recipients is excreted into the urine through the transplanted kidney, which results in AKI through oxalate crystal deposition in the transplanted kidney and is the reason for the delayed recovery of renal function. A meta-analysis by Lumlertgul et al. [21] pointed out that the prognosis of secondary renal oxalosis was poor, with more than half of the patients needing to rely on dialysis. Based on the follow-up data in the present study, in addition to severe glomerular damage that renders some critically ill patients unable to stop dialysis, oxalosis not only reflects renal tubular damage, but also indicates partial irreversibility of tubular injury.

In conclusion, we confirm that the majority of oxalosis occurred in AKD were critically ill patients, secondary to kidney injury with tubular injury. Severe oxalosis contributed to delayed early recovery of renal function. Therefore, there is an urgent need to develop novel strategies that can interfere with oxalate crystal formation to achieve better renal outcomes.

\section{Abbreviations}

AKD: acute kidney disease; AKI: actue kidney injury; TIN: tubulointerstitial nephritis; GD, glomerular disease; CKD, chronic kidney disease; GFR, glomerular filtration rate; NAG: N-acetyl- $\beta$-D-glucosaminidase; a1-MG:a1-microglobulin; T-IS: tubular injury score

Page $11 / 14$ 


\section{Declarations}

\section{Ethics approval and consent to participate}

The study was performed in compliance with the Declaration of Helsinki and approved by the Ethics Committee of Peking University First Hospital (approval number 2017[1280]). The need for informed consent was waived because of the retrospective nature of the study.

\section{Consent for Publication}

Not applicable.

\section{Availability of data and materials}

These patients were followed up and the clinical data is traceable. The datasets used and analysed during the current study are available from the corresponding author on reasonable request.

\section{Competing interests}

No one of the authors has a financial and non-financial competing interest.

\section{Funding}

This work was supported by grants of the National Science and Technology Major Projects for Major New Drugs Innovation and Development of China (No. 2017ZX09304028), National Natural Science Foundation of China (Nos.91742205 and 81625004), and Chinese Academy of Medical Sciences Innovation Fund for Medical Sciences (No. 2019-I2M-5-046).

\section{Authors' Contributions}

J.Z. designed the study, performed acquisition, analysis, interpretation of data, and drafted the manuscript. X.-J.Y. and S.-X.W. were involved in data acquisition. L.Y. contributed to the study idea and interpretation of data supervised the work. T.S. conceived the study, revised the manuscript, and provided intellectual content of critical importance to the work. Each author gave final approval of the version to be published.

\section{Acknowledgements}

The authors thank Alison Sherwin, PhD, from Liwen Bianji, Edanz Group China (www.liwenbianji.cn/ac) for editing the English text of a draft of this manuscript.

\section{References}

1. Karaolanis G, Lionaki S, Moris D, et al. Secondary hyperoxaluria: a risk factor for kidney stone formation and renal failure in native kidneys and renal grafts. Transplant Rev (Orlando). 
2014,28(4):182-87

2. Mulay SR, Shi C, Ma X, et al. Novel Insights into Crystal-Induced Kidney Injury. Kidney Dis (Basel). 2018,42(2):49-57.

3. Zeng SH, Liu XQ. Oxalate nephropathy-new concept o metabolic nephropathy.Chin J Nephrol,1998, (03):193-96.

4. Liang SS, Zeng $\mathrm{CH}$. Diabetic nephropathy complicated with acute calcium oxalate kidney injury. Chin J Nephrol Dial Transpl, 2016,25(2):191-94.

5. Tsai JL, Tsai SF. Calcium oxalate crystal related kidney injury in a patient receiving Roux-en $Y$ hepaticojejunostomy due to gall bladder cancer. BMC Nephrol.2017,18(1):106..

6. Ligon CB, Hummers LK, McMahan ZH. Oxalate nephropathy in systemic sclerosis:Case series and review of the literature. Semin Arthritis Rheum. 2015,45(3):315-20.

7. Hashimoto S, Yamamoto R, Maoka T, et al. A Case of Chronic Calcium Oxalate Nephropathy due to Short Bowel Syndrome and Cholecystectomy. Case Rep Nephrol Dial. 2018,8(2):147-154.

8. Khwaja A. KDIGO clinical practice guidelines for acute kidney injury. Nephron Clin Pract. 2012,120(4):c179-c184.

9. Chawla LS, Bellomo R, Bihorac A, et al. Acute kidney disease and renal recovery: consensus report of the Acute Disease Quality Initiative (ADQI) 16 Workgroup. Nat Rev Nephrol.2017,13: 241-257..

10. Racusen LC, Solez K, Colvin RB, et al. The Banff 97 working classification of renal allograft pathology[J]. Kidney Int. 1999,55(2):713-23.

11. Solez K, Colvin RB, Racusen LC, et al. Banff 07 classification of renal allograft pathology: updates and future directions. Am J Transplant. 2008,8(4):753-60.

12. Getting JE, Gregoire JR, Phul A, et al. Oxalate nephropathy due to 'juicing': case report and review. Am J Med. 2013,126(9):768-72.

13. Mulay SR, Anders HJ. Crystal nephropathies: mechanisms of crystal-induced kidney injury[J]. Nat Rev Nephrol. 2017,13(4):226-40.

14. Jiang H, Pokhrel G, Chen Y, et al. High expression of SLC26A6 in the kidney may contribute to renal calcification via an SLC26A6-dependent mechanism. PeerJ. 2018,6:e5192.

15. Salyer WR, Keren D. Oxalosis as a complication of chronic renal failure. Kidney Int. 1973,4(1):61-6.

16. Prenen JA, Dorhout Mees EJ, Boer P. Plasma oxalate concentration and oxalate distribution volume in patients with normal and decreased renal function. Eur J Clin Invest. 1985,15(1):45-9.

17. Ermer T, Eckardt KU, Aronson PS, et al. Oxalate, inflammasome, and progression of kidney disease. Curr Opin Nephrol Hypertens. 2016,25(4):363-71.

18. Cao Y, Liu W, Hui L, et al. Renal tubular injury induced by ischemia promotes the formation of calcium oxalate crystals in rats with hyperoxaluria. Urolithiasis. 2016,44(5):389-97.

19. Knauf $\mathrm{F}$, Velazquez $\mathrm{H}$, Pfann $\mathrm{V}$, et al. Characterization of renal $\mathrm{NaCl}$ and oxalate transport in Slc26a6-/- mice[J]. Am J Physiol Renal Physiol. 2019,316(1):F128-F133. 
20. Efe O, Verma A, Waikar SS. Urinary oxalate as a potential mediator of kidney disease in diabetes mellitus and obesity. Curr Opin Nephrol Hypertens. 2019,28(4):316-20.

21. Lumlertgul N, Siribamrungwong, Jaber BL, et al. Secondary Oxalate Nephropathy: A Sys-tematic Review. Kidney Int Rep. 2018,3(6):1363-372.

\section{Figures}
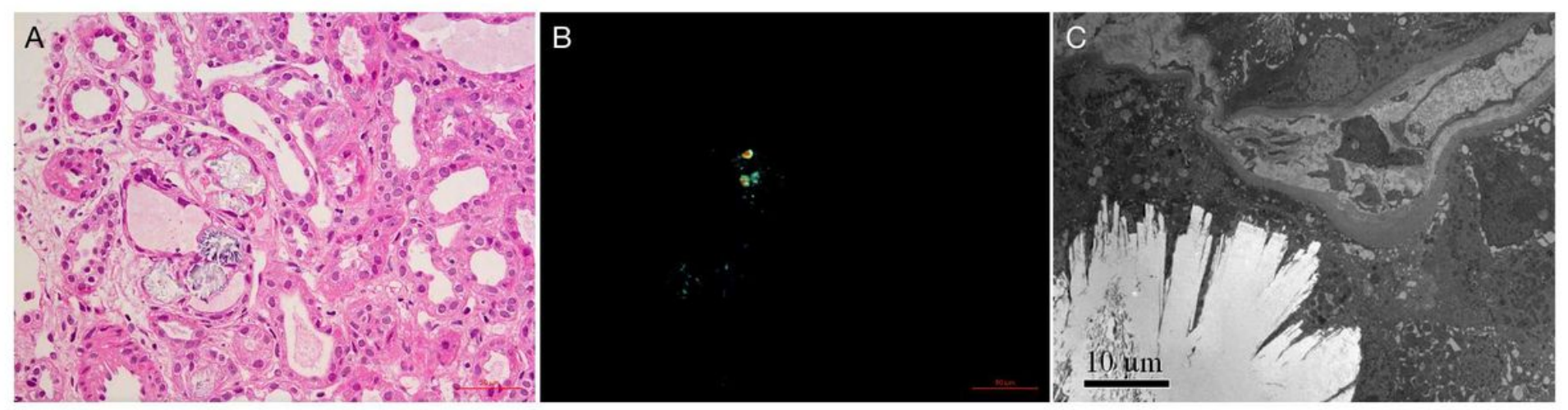

\section{Figure 1}

Renal oxalate crystal deposit. A. Transparent or light brown crystal structures can be seen under light microscope (HE, x400); B. Birefringent crystals can be seen under polarized light microscope (HE, x400). C. Clusters of needle-like crystal structures under electron microscope (x3000). 